\title{
PROBLEMA
}

\section{SOBRE LA JUSTIFICACIÓN RACIONAL DE LAS NORMAS: CONSIDERACIONES A PARTIR DE LAS IDEAS DE SERGIO COTTA}

\author{
Carlos I. MASSINI CORREAS
}

\begin{abstract}
Resumen:
El presente artículo desarrolla el problema de la justificación racional del derecho en general y de las normas jurídicas en particular, ante las corrientes de pensamiento denominadas posmodernas que niegan la posibilidad y validez de tales intentos. El trabajo ofrece una reseña acerca de la justificación racional de las normas a partir de la novedosa doctrina de Sergio Cotta, quien es uno de los autores que ha abordado el tema con mayor extensión y consistencia. A lo largo del artículo, el autor intenta mostrar de qué manera está fundada la elección de una norma, explica las nociones centrales de la doctrina de Cotta, identifica sus aciertos, sus debilidades, su conexión con la teoría del conocimiento práctico y concluye con algunas observaciones al modelo de justificación propuesto.
\end{abstract}

\section{Palabras clave:}

Justificación racional de las normas, juicios de valor, proposiciones normativas, discurso ético.

\section{Abstract:}

This paper analyzes the problem of rational justification of law in general and legal norms in particular, a problem highlighted by the so-called 


\section{CARLOS I. MASSINI CORREAS}

postmodern trends that deny the possibility and validity of these attempts. While the postmodern trends serve as a background to the discussion, the article provides a summary of rational justification of norms based on Sergio Cotta's innovative approach, who is arguably one of the authors that has dealt to the topic with more prominence and consistency. Thus, the goal of this article is to point out how the election of a norm can be justified, and to explain the main notions of Cotta's approach, in order to assess his accuracy and weakness, and his connection to the theory of practical knowledge. The article concludes with some remarks on Cotta's justification model.

\section{Keywords:}

Rational Justification of Norms, Value Judgments, Normative Propositions, Ethical Discourse. 
Sumario: I. Posmodernidad y justificación. II. Cotta y el planteo de la cuestión. III. La respuesta de Cotta. IV. Reflexiones valorativas: Cotta y la justificación de las normas. V. Excurso: la teoría del conocimiento práctico. VI. Debilidades de la justificación analizada. VII. Consideraciones conclusivas.

\section{POSMODERNIDAD Y JUSTIFICACIÓN}

En su emblemático libro Nihilismo y emancipación, Gianni Vattimo, reconoce lisa y llanamente, y refiriéndose específicamente al derecho, que "los constituyentes y legisladores, al aclarar las intenciones que los llevan a establecer un cierto principio o una determinada ley, se remontan siempre, ellos también, a un "ya" que, en el límite, puede ser el mismo derecho (considerado) natural"; agregando luego que

la constante presencia de la idea de derecho natural en la tradición jurídica y filosófica es un claro indicio del hecho de que toda legitimidad necesita un precedente, es más, se reduce a encontrar un precedente - ciertamente un precedente con autoridad, la cual consiste a su vez, sin embargo, en derivar de un precedente ulterior, también con autoridad, etcétera-. ${ }^{1}$

Pero pocas páginas más adelante, y expresando ahora sus propias convicciones, sostiene que

...hay que tomar en consideración el significado nihilista de la metafísica en todo su alcance. Ello puede darse de diferentes maneras. El pensamiento que se percata de la insuperable falta de fundamentación que marca últimamente al derecho, haciendo inútil todo esfuerzo por legitimarlo como "justo", puede decidir que su tarea es la de desvelar esta situación desenmascarando la impostura de toda pretensión fundamentadora. ${ }^{2}$

1 Vattimo, G., Nihilismo y emancipación. Ética, politica, derecho, trad. de C. Revilla, Barcelona, Paidós, 2004, p. 157.

2 Ibidem, p. 161. 
Esta negativa radical de la posibilidad - y validez- de los intentos filosóficos de fundamentación racional del derecho, son una constante en las corrientes de pensamiento denominadas posmodernas, ${ }^{3}$ que hacen del nihilismo ${ }^{4}$ una profesión de fe filosófica. Ahora bien, esta concepción de la razón como incapaz de justificar racionalmente sus afirmaciones de carácter normativo, así como de toda verdad que no se reduzca a mera emancipación — "es verdad sólo lo que os libera",5 afirma Vattimo - es claro que priva al derecho de su misma existencia, ya que, como lo ha mostrado una vez más Robert Alexy, el derecho consiste en su obligatoriedad y fuera de ella pierde todo sentido y consistencia. Refiriéndose específicamente a los derechos humanos, este último autor sostiene que "un derecho vale éticamente si puede ser fundamentado frente a cada uno que participe en una justificación racional. La validez de los derechos humanos es su existencia. La existencia de los derechos humanos consiste por ende - concluye- en su fundamentabilidad y en nada más". 6

Dicho en otras palabras, privado de toda justificación racional de su obligatoriedad —que no puede ser sino ética-7 el derecho, sea el normativo, el subjetivo o el conductual, ${ }^{8}$ deja de ser tal para reducirse a una mera expresión de deseos, a un nudo acto de voluntad o a una simple expresión emotiva, privadas de todo carácter vinculante y

3 En este punto, véase Massini Correas, C. I., "La teoría del derecho natural en el tiempo posmoderno”, Doxa, Alicante, núm. 21-II, 1998, pp. 289-303.

4 Sobre el concepto de nihilismo y sus versiones, véase Volpi, F., El nihilismo, trad. De C. del Rosso \& A. Vigo, Buenos Aires, Biblos, 2005. Véase también Reale, G., Saggezza Antica, Milán, R. Cortina Editore, 1995, y Possenti, V., Nichilismo e Metafisica, Roma, Armando Editore, 2004.

5 Vattimo, G., cit., p. 10.

6 Alexy, R., "Menschenrechte ohne Metaphysik?", Deutsche Zeitschrift für Philosophie, núm. 52, 2004, p. 16.

7 Véase Finnis, J., Natural Law and Natural Rights, Oxford, Clarendon Press, 1984, pp. 297 y ss. En este punto, véase Pereira, C., La autoridad del derecho. Análisis crítico de la posición de J. M. Finnis, La Coruña, pro manuscripto, 2007, pp. 272 y ss.

8 Acerca del carácter analógico del concepto de derecho, véase Massini Correas, C. I., Filosofía del derecho-I-El derecho, los derechos humanos y el derecho natural, Buenos Aires, Lexis Nexis, 2005, pp. 31 y ss. 
directivo de la vida humana jurídica. Expresado aún más brevemente: un derecho sin obligatoriedad no es derecho y una obligatoriedad injustificada, deja lisa y llanamente de serlo, para transformarse en una entidad de una indole o clase diferente.

Resulta, por lo tanto, indispensable encarar el problema de la justificación racional del derecho, en especial de las normas jurídicas, a los fines de dar cuenta de la existencia misma del derecho en cuanto constitutivo-directivo de toda una dimensión de la vida humana. Uno de los autores que abordó esa tarea con más extensión y consistencia fue el recientemente desaparecido Sergio Cotta, quien dedicó todo un libro - Giustificazione e obligatorietà delle norme- ${ }^{9}$ al desarrollo de una doctrina de la justificación racional de las normas, doctrina que reiteró luego en otros trabajos y con respecto a otras dimensiones de la realidad jurídica. ${ }^{10} \mathrm{En}$ las páginas que siguen, se efectuará una reseña de sus ideas en este punto, para concluir luego con algunas breves consideraciones valorativas.

\section{CotTtA Y EL PLANTEO DE LA CUESTIÓN}

Cotta ha sintetizado su teoría acerca de la justificación racional de las normas en un trabajo publicado en francés con el título "Le problème de la justification scientifique des normes", 11 al que se seguirá principalmente en lo que sigue, en razón de las exigencias de brevedad que han sido impuestas a este trabajo. El profesor italiano comienza - no podía ser de otra manera- por estudiar la cuestión de la 1981.

9 Cotta, S., Giustificazione e obligatorietà delle norme, Milán, Giuffrè Editore,

10 Respecto de la problemática de los derechos humanos y su justificación racional, véase Cotta, S., "Le problème du fondement des droits de l'homme", Memoria del X Congreso Mundial de Filosofía del Derecho y Filosofía Social, Curiel, J. L. (comp.), México, UNAM, 1982, t. VI, pp. 39-50.

11 Cotta, S., "Le problème de la justification scientifique des normes" (en adelante PJ), Rivista Internazionale di Filosofia del Diritto, núm. LVI-1, Milán, 1979, pp. 5-20. 
necesidad misma de una justificación científica, i.e., racional, de las normas, cuyo primer paso consiste en verificar la insuficiencia de la mera promulgación o enunciación para que ellas adquieran obligatoriedad y resulten efectivas. Esta insuficiencia, sostiene Cotta, se da ante todo en el plano de los hechos, ya que "para eliminar por la fuerza toda transgresión sería necesario ejercerla continuamente sobre cada destinatario de la norma, lo que es prácticamente imposible". 12

Pero no sólo desde el punto de vista empírico es insuficiente la mera promulgación, sino también desde una perspectiva teórica; en efecto, para Cotta, las normas son la condición trascendental de la trasgresión, que no existe en sentido propio sin la existencia de las normas, las cuales son su condición de posibilidad. De este modo,

...si la trasgresión es posible - escribe Cotta - tanto por razones de orden fáctico como de orden teórico, es evidente que la enunciación de las normas no es suficiente para negarla o impedirla. Es por lo tanto indispensable indicar las razones por las cuales se ha elegido, de entre las alternativas de acciones posibles, aquella que debe ser; es decir, que es necesario justificar la norma mostrando que esta elección no es arbitraria, sino que está fundada de un modo u otro. ${ }^{13}$

Esta justificación consiste - según este autor- en el procedimiento intelectual por el cual se intenta dar razón, a través de argumentos verificables o falsables, de la imposibilidad de negar la obligatoriedad de una proposición prescriptiva o prohibitiva.

Luego de esta argumentación, Cotta se hace cargo de la objeción levantada por las teorias críticas contra la necesidad y posibilidad de una justificación racional de las normas. Según estas teorías, la transgresión existe en virtud de la norma; es por lo tanto una posibilidad idéntica a la posibilidad imperada por la norma, con lo que se plantea

12 PJ, p. 6.

13 PJ, p. 8. 
la alternativa, que es percibida por estas teorias como superadora, de permitir la realización de todas las posibilidades, aboliendo todas las normas, que no son percibidas sino como una limitación antinatural y puramente represiva del libre desenvolvimiento de las posibilidades; no habría por lo tanto ninguna necesidad de justificar las normas: sólo habria que abolirlas. ${ }^{14}$

Para Cotta, por el contrario, "el rechazo total de la normatividad implica la reducción integral del deber ser al ser, y consecuentemente supone la supresión del discurso ético en sí mismo". Este rechazo frontal de la ética hace por lo tanto necesario responder a la pregunta radical: "¿por qué la ética y no su ausencia?”. Para responderla, sostiene Cotta que es necesario sobrepasar el estricto dominio del deber ser y considerar su relación con el dominio del ser:

Nos aparece entonces - escribe este autor-que la exigencia del deber ser (...) deriva y se impone del hecho de que el existente (l'étant) (el human being, el Seiende) no es solitario ni autosuficiente, no es un simple existente sino un co-existente. El ser de nuestro ser-aquí (das Sein des Dasein), para expresarse en términos heideggerianos, es un co-ser (...). El discurso ético tiene un sentido sólo al interior de un horizonte ontológico delimitado por la insuficiencia-indigencia del existente y por su co-existencialidad. Tal es el fundamento de la necesidad del deber ser (de la normatividad moral y jurídica) $\mathrm{y}$, más en general, del discurso ético (...), que como consecuencia son exigidos por la co-existencialidad y tienen a la co-existencia como finalidad. ${ }^{15}$

\section{LA PROPUESTA DE COTTA}

Una vez establecida la necesidad de una justificación de las normas, Cotta comienza el desarrollo de su propio intento de justificación, el que comienza por la afirmación de que toda justificación deberá mostrar: (i) que el acto norma-

14 Véase PJ, p. 9.

15 PJ, pp. 9 y 10. 
do es posible, cosa que considera indiscutible y que es innecesario desarrollar, y (ii) que el acto posible prohibido es desaprobable y que el acto posible prescrito es aprobable. Pero tanto la aprobación como la desaprobación reenvian a valores, que es necesario justificar a su vez. ${ }^{16}$ Ahora bien, existen varios intentos de alcanzar esta justificación, tanto en el nivel cotidiano y pre-científico, como en el propiamente científico-argumentativo. En el primero de estos niveles, las principales propuestas de justificación son dos: por la autoridad que promulga la norma y por la ideología que la inspira. Ambas son recusadas por Cotta en razón de que presuponen tanto la autoridad de quien promulga las normas, cuanto el valor de la ideología que las inspira, y "no proveen de argumentos capaces de probar directa y objetivamente el fundamento suficiente de la prescripción normativa, es decir, las razones por las cuales un comportamiento posible ha de ser preferido a otros para ser elevado al rango de comportamiento que debe ser". ${ }^{17}$

En cuanto a los ensayos de justificación científica de las normas, Cotta afirma que ellos deberán cumplir ciertas condiciones inexcusables para ser tales: (i) sobrepasar el nivel de la mera verificación de su eficacia; (ii) ser universales, y (iii) no reenviar a presupuestos, principios o sistemas que no estén a su vez justificados. ${ }^{18}$ Estas condiciones permiten mostrar la insuficiencia de varios de los ensayos contemporáneos de justificación de las normas, en especial la de la Reine Rechtslehre de Hans Kelsen, que las justifica a partir de una Grundnorm sólo presupuesta pero nunca justificada en sí misma. Y en lo que respecta a la teoría propuesta por la escuela escandinava, Cotta sostiene que, para esa escuela, "la única explicación científica del carácter obligatorio de un sistema normativo consiste en la constatación empírica del hábito de obedecerlo y de la presión psicológica que ejerce sobre los ciudadanos"; y concluye que

\footnotetext{
16 Véase $P J$, p. 11.

17 PJ, p. 12.

18 Idem.
} 
"como el hábito y la presión psicológica son justificaciones sólo de la obediencia al sistema, este mismo queda injustificado, a menos que el sólo hecho de existir sea considerado suficiente para justificar su obligatoriedad", ${ }^{19}$ cosa que resulta lisa y llanamente absurda.

Ahora bien, como tampoco la mera coherencia interna del sistema normativo es suficiente para justificarlo, ya que se trataría de una clara petición de principio, Cotta propone un ensayo de justificación normativa de carácter funcional, basada en un discurso teorético, de carácter veritativo. ${ }^{20}$ En este ensayo de lo que se trata es de demostrar a través de un discurso alético, i.e., susceptible de verdad o falsedad, que el contenido de las normas es aprobable o bien desaprobable. Cotta recuerda que para el no-cognitivismo $^{21}$ esto no es posible, toda vez que esa posición sostiene que "la determinación de que una aserción es verdadera (...) no autoriza a inferir que el comportamiento indicado es éticamente aprobable (...) y por lo tanto que la norma correspondiente (...) está justificada”.22 Sin embargo, para Cotta, la verdad de un enunciado teórico no carece de importancia para una justificación de las normas, como sucede cada vez que esa norma (v.gr. que se debe obedecer a las leyes de la comunidad política) pueda ser relacionada necesaria y funcionalmente con una proposición teórica verdadera (v.gr. que la obediencia a las leyes es necesaria para la existencia de la comunidad política). "En consecuencia - concluye este autor - la norma que prescribe un acto funcional al ser de una situación existencial común, permanece siendo una norma, porque ella discrimina, entre varios actos fácticamente posibles, aquel que debe (o no debe)

19 PJ, p. 13.

20 PJ, p. 15.

21 Sobre el no-cognitivismo ético, Cotta ha escrito palabras decisivas en un sugerente trabajo: Cotta, S., "Conoscenza e normatività. Una prospettiva metafisica", Rivista Internazionale di Filosofia del Diritto, Milán, núm. LXXI, 1994, pp. 555-568.

22 PJ, p. 15. 
ser", ${ }^{23}$ vinculándolo en su estructura al imperativo hipotético de Kant.

Pero el mismo Cotta reconoce el carácter limitado de esta justificación funcional, en razón de que ella está limitada al contexto dentro del cual se realiza -en el caso del ejemplo, la comunidad política- y al hecho de que este contexto no sea recusado por los participantes -en el ejemplo, los mismos integrantes de la comunidad politica- Cotta propone entonces como alternativa una justificación de tipo hipotético-asertórico o pragmático, según la cual el objetivo que justifica las normas no está limitado a una comunidad, sino que se trata de hecho de un objetivo compartido por la totalidad de los seres humanos, i.e., de carácter universal.24

Ahora bien, sucede que este argumento también tiene sus limitaciones, ya que se refiere a objetivos, como la felicidad de los seres humanos individuales, i.e., a la existencia individual y no a la coexistencia, que es donde - según Cotta - el discurso ético adquiere un sentido. Y pone como ejemplo el enunciado "el respeto del inocente es necesario para la existencia humana", que sólo adquiere sentido en el marco de la coexistencia:

Esto nos permite precisar - afirma este autor- que el imperativo asertórico es justificable de un modo (...) incontrovertible y por lo tanto científico, desde que concierne a aquello que es necesario no a la existencia individual sino a la coexistencia interhumana (...); la coexistencia - concluyeno es en sí misma, inmediatamente, un valor, pero llega a serlo cuando se lo asume, por la intencionalidad, como criterio supremo de toda acción. ${ }^{25}$

Y este valor reviste un carácter teórico-asertórico toda vez que puede probarse la universalidad de su apreciación ética y de su consiguiente valor moral. ${ }^{26}$ De este modo, Cotta considera que es posible justificar las normas de modo cien-

\footnotetext{
23 PJ, p. 16.

24 PJ, pp. 16 y 17.

25 PJ, p. 18.

26 Véase $P J$, p. 19.
} 
tífico, i.e., a partir de una enunciación teórica — como la del valor de la coexistencialidad humana- susceptible de verdad y por lo tanto de cientificidad. ${ }^{27}$

Cotta ejemplifica todo esto a partir del ya referido enunciado teórico "el respeto del inocente necesario a la existencia humana",28 al que considera "reciprocable" (réciprocable), ${ }^{29}$ universalizable y necesario, no sólo a la existencia individual, sino para la co-existencia. Cotta sostiene que este enunciado no es inmediatamente falsable, por lo cual, "si la verdad del enunciado teorético resulta establecida, ella otorgará la justificación funcional de la norma correspondiente "tú debes respetar al inocente", que es indispensable porque el comportamiento opuesto permanece como fácticamente posible". ${ }^{30} \mathrm{Y}$ concluye - siguiendo en este punto un argumento elaborado por Gaetano Carcaterra para pasar de proposiciones de ser a otras de deber ser-31 que la afirmación acerca de la necesidad para la coexistencia del respeto al inocente, es aceptada por todos, razón por la cual es legítimo concluir de ella la justificación racional de la norma que la prescribe. ${ }^{32}$

\section{REFLEXIONES VALORATIVAS: COTTA Y LA JUSTIFICACIÓN DE LAS NORMAS}

Una vez expuesto sucintamente el ensayo realizado por Cotta de elaborar un modelo de justificación de las normas de carácter teorético y veritativo, corresponde efectuar a su

27 Esto último se encuentra bastante más desarrollado, pero sin modificaciones en cuanto a la doctrina, en Cotta, S., Giustificazione..., cit., pp. 109-117.

28 PJ, p. 17.

29 Esta palabra — que designa la cualidad de ser susceptible de reciprocidadno existe en el idioma castellano, pero tampoco existe en francés la que utiliza Cotta, al menos si se está a lo contenido en el Diccionario Larousse.

30 PJ, p. 18.

31 PJ, pp. 18 y 19.

32 En el "Apéndice" a su libro Giustificazione e obligatorietà delle norme (pp. 139-152), Cotta reelabora esta justificación el términos de una ontología fenomenológico-existencial de raíz hideggeriana, pero - a criterio del autor de estas líneas- no varía en lo sustancial la argumentación desarrollada hasta aquí. 
respecto algunas consideraciones de carácter valorativo, poniendo en evidencia tanto los aspectos positivos como las debilidades de la propuesta. Ante todo, es preciso reconocer el esfuerzo de rigor y coherencia realizado por el autor, que reviste mayor relevancia por tratarse en este caso de una elaboración filosófica de carácter mayormente personal, que si bien reconoce necesariamente deudas intelectuales, adquiere una formulación y una estructura novedosas y en buena medida originales. Y esto no es poco, en especial cuando, como fue siempre el caso de Cotta, se "nada contra la corriente" 33 de las modas filosóficas hodiernas.

Pero este nadar contra la corriente adquiere además un especial valor cuando lo que se intenta es una reivindicación de la razón en un campo, como el de la ética y el derecho, donde se encuentra cuestionada en toda la línea. Desde el escepticismo moderno encabezado por Hume, pasando por el Círculo de Viena y su secuela de emotivismo ético y por las corrientes de la "filosofia de la sospecha", para terminar en el actual nihilismo ético, se ha intentado socavar la posibilidad de una justificación racional y veritativa de las realidades prácticas, ya sea reduciendo su sentido al otorgado por el sujeto o la cultura, o bien eliminando de raíz toda posibilidad de sentido. Pero sucede que, como lo ha evidenciado Kalinowski al comentar un libro de Cotta, "si las normas jurídicas no están justificadas no obligan, dicho de otro modo, no están en vigor. Ellas no tienen fuerza obligatoria si no están justificadas". ${ }^{34}$

Esto es así porque pertenece a la índole de la normatividad humana - en rigor, no existe otra - el dirigirse a una razón justificándose en razones; y estas razones no pueden ser sino objetivas, i.e., referidas a una realidad con una existencia distinta del sujeto que las formula y cognoscible de modo verdadero, ya que de lo contrario se cae en el sub-

33 La expresión está tomada del título del libro de Veatch, H. B., Swimming Against the Current in Contemporary Philosophy, Washington D. C., CUA Press, 1990.

34 Kalinowski, G., "Compte Rendu a Giustificazione e obligatorietà delle norme", Archives de Philosophie du Droit, París, núm. 29, 1984, p. 422. 
jetivismo ético que en definitiva, como lo ha mostrado acertadamente Cotta, "no hace más que expresar la lógica de la potencia, el tantum iuris tantum potentiae de Spinoza, que hace imposible la co-existencia humana y vacía de sentido (senseless) toda afirmación ética (...). Brevemente, el subjetivismo ético no puede renunciar a justificar objetivamente sus juicios de valor a menos de dejar de ser propiamente ético". 35

Pero está claro que esta justificación racional y objetiva supone - para ser tal- un discurso veritativo, que Cotta denomina "alético", y que consiste en la posibilidad de una adecuación de los enunciados que la componen con alguna realidad independiente de los meros pensamientos del sujeto que intenta esa justificación. ${ }^{36}$ Por otra parte, en varios lugares el autor italiano deja en claro que los enunciados básicos que conforman la justificación racional que propone revisten carácter teórico y por lo tanto la verdad que los tiene por objeto es una verdad teorética. "Se trata de proposiciones -escribe Cotta- evidentemente teoréticas, no sólo porque están formuladas en el modo verbal indicativo, sino sobre todo porque describen situaciones de ser (essere). Su verdad es, por lo tanto, controlable (verificable o falsable) empíricamente". ${ }^{37}$

Ahora bien, frente a estas afirmaciones inequívocas, es preciso reiterar una pregunta clásica, pero no por ello desprovista de valor: ¿es posible justificar racionalmente proposiciones normativas con el sólo concurso de proposiciones teoréticas?; ¿no aparecerá es ese caso, algo nuevo en las conclusiones, que no estaba contenido en las premisas, tal como lo denunciara en su momento - aunque en definitiva

35 PJ, p. 20.

36 Sobre la noción de verdad que se usará en este contexto, véase Inciarte, F., "El problema de la verdad en la filosofia actual: verdad y sentido", El reto del positivismo lógico, Madrid, Rialp, 1974, pp. 54-81, y Vigo, A. G., "El concepto de verdad teórica en Aristóteles. Intento de reconstrucción sistemática”, Estudios aristotélicos, Pamplona, EUNSA, 2006, pp. 107-154.

37 Cotta, S., Giustificazione..., cit., p. 102. 
de modo erróneo- David Hume?;38 ¿resulta consistente una justificación racional de enunciados prácticos elaborada a partir solamente de afirmaciones teórico-descriptivas? Y la pregunta es en este caso especialmente pertinente, ya que Cotta elaboró gran parte de su filosofia del derecho en oposición activa a las corrientes analíticas de la iusfilosofia, que asumian sistemáticamente la imposibilidad de esa derivación. ${ }^{39}$ Por ello, sin compartir necesariamente las afirmaciones - y las limitaciones- de la filosofia analítica del derecho -en rigor, habria que hablar de positivismo analitico - resulta indispensable abordar esas preguntas, ya que las diferentes respuestas posibles condicionan la solución válida a la cuestión de la justificación racional de las normas.

\section{EXCURSO: LA TEORÍA DEL CONOCIMIENTO PRÁCTICO}

Un intento de respuesta a estas cuestiones requiere ante todo la realización de algunas precisiones liminares, la primera de las cuales radica en la distinción, en el marco de las proposiciones y de sus enunciados, entre las proposiciones ${ }^{40}$ (y sus correspondientes enunciados) teóricas, prácticas y poiéticas (que pueden llamarse también técnicas y que se dejarán de lado en lo sucesivo). Teóricas son aquellas proposiciones que designan hechos, situaciones o estados de cosas; por su parte, son prácticas aquellas proposiciones

38 Hume, D., A Treatise on Human Nature. An Attempt to Introduce the Experimental Method of Reasoning into Moral Subjects, Londres, Penguin Classics, 1985, p. 521. Sobre este texto, véase Fate Norton, D., "Hume, Human Nature, and the Foundations of Morality", en varios autores, The Cambridge Companion to Hume, Fate Norton, D. (ed.) Cambridge, Cambridge U.P., 1998, pp. 148-181.

39 Véase Jori, M., "Introduzione", Ermeneutica e filosofia analitica. Due concezione del diritto a confronto, Jori, M. (ed.), Torino, Giappichelli, 1994, pp. 17 y ss. Sobre esta oposición de escuelas, véase Massini Correas, C. I., "Entre la analítica y la hermenéutica. La filosofia jurídica como filosofia práctica", Persona y Derecho, Pamplona, núm. 56, 2007, pp. 205-243.

40 Por supuesto que también existen conceptos prácticos — que no se tratarán aquí- y razonamientos prácticos; véase Kalinowski, G., "La razón práctica: sus conceptos, juicios y razonamientos", Anales de la Cátedra Francisco Suárez, Granada, núm. 17, 1977, pp. 201-216. 
que dirigen $-\mathrm{o}$ valoran con referencia a su dirección- la acción propiamente humana, sea cual sea su estructura sintáctico-gramatical. A su vez, ambas son el resultado de un conocimiento, teórico en el primer caso y práctico en el segundo. Corresponde hacer notar que en el concepto de proposiciones teóricas incluye no sólo aquellas que describen hechos cognoscibles empíricamente (v.gr. "este caballo es flaco"), sino también aquéllas construidas por conceptos abstractos (v.gr. "el hombre piensa"). Por su parte, las proposiciones prácticas pueden ser divididas - conforme las enseñanzas de Georges Kalinowski- en estimativas, normativas e imperativas. ${ }^{41}$

Pero si se limita el análisis a las proposiciones normativas, éstas pueden ser clasificadas a su vez, según su mayor o menor universalidad, en principios (o normas primeras), normas en sentido estricto, que conservando un cierto grado de universalidad se refieren a acciones o situaciones genéricamente consideradas, y preceptos prudenciales, que consisten en una directiva concreta, i.e., máximamente determinada, ${ }^{42}$ acerca de una conducta humana. Ahora bien, las proposiciones prácticas, ya sean estimativas, normativas o imperativas y se trate de principios, normas generales o preceptos prudenciales, pueden ser - siguiendo aquí una tradición que se remonta a la Ética Nicomaquea de Aristóteles- verdaderas o falsas. ${ }^{43}$ Esto en razón de que expresan un conocimiento, que en cualquier caso habrá de ser verdadero - si es tal conocimiento- o bien falso -en el caso de no resultar tal-.

Dado esto por sentado, y si se acepta la definición de verdad propuesta por Aristóteles: "Decir de aquello que es, que

41 Véase Kalinowski, G., El problema de la verdad en la moral y en el derecho, trad. de E. Marí, Buenos Aires, EUDEBA, 1979, pp. 101 y ss.

42 Véase Soaje Ramos, G., "La verdad práctico-moral, desde Aristóteles al Aquinate (Una consideración gnoseo-epistemológica)", Ethos, Buenos Aires, núm. 23-25, 1997, pp. 274 y ss.

43 Véase en este punto Warne, Ch., Aristotle's Nicomachean Ethics, Londres-Nueva York, Continuum, 2006, pp. 79 y ss. 
es, y de aquello que no es, que no es, es decir la verdad", ${ }_{44}$ será verdadera aquella proposición teórica que expresa una relación idéntica a la existente en la realidad, v.gr., la proposición "la puerta está cerrada" será verdadera si y sólo si la puerta está —en la realidad - cerrada. Del mismo modo, la proposición práctico-normativa "el depositario debe devolver el depósito", será verdadera si efectivamente el depositario debe devolver el depósito, relación deóntica de deber que puede tener su fundamento tanto en la ley jurídica natural como en la positiva. ${ }^{45}$

Finalmente, corresponde consignar que todo lo anterior es estudiado por una rama de la filosofia que se ha dado en denominar filosofía práctica, que contiene necesariamente - entre otros temas relevantes - una teoría del conocimiento práctico, la parte de esa filosofia que estudia la especificidad del conocimiento práctico respecto del teórico, los planos y niveles de ese conocimientos, los conceptos, juicios y raciocinios prácticos, la lógica de las proposiciones prácticas, en especial las normativas, la teoría de la verdad práctica, asî como otros temas vinculados directamente con los enumerados. ${ }^{46}$

Ahora bien, una de las afirmaciones centrales de la teoría del conocimiento práctico es que la justificación racional de las proposiciones prácticas, en especial las normativas, ha de contener necesariamente en sus premisas al menos una proposición práctica, en el caso que aquí nos interesa, práctico-normativa. Y esto es necesariamente así, toda vez que no es legítimo desde el punto de vista lógico inferir $-\mathrm{y}$ por ende justificar- proposiciones normativas a partir sólo de proposiciones teóricas, toda vez que no puede aparecer en la conclusión algo - en este caso la normatividad- que

44 Aristóteles, Metafísica, 1011 b 27.

45 Véase Massini Correas, C. I., "Iusnaturalismo e interpretación jurídica", en varios autores, La interpretación en la era del neoconstitucionalismo, Cianciardo, J. (ed.), Buenos Aires, Ábaco, 2006, pp. 57-81.

46 Kalinowski, J., "De la philosophie pratique a la logique déontique", en varios autores, Saint Thomas d'Aquin, pour le septième centenaire de sa mort, Kaminski, S. (eds.) et al., Lublin, WTNKUL, 1975, pp. 224 y ss. 
no se encuentre antes en las premisas, ${ }^{47}$ ya que si apareciera no se trataria propiamente de una inferencia sino de una inclusión gratuita. Por otra parte, es necesario que en las premisas de un razonamiento que concluye en una proposición normativa exista al menos una proposición de ese tipo, porque sólo de ese modo la conclusión puede revestir carácter normativo (la conclusión sigue siempre a la premisa más débil, que viene a serlo siempre la normativa por su carácter análogo al de las proposiciones modales). ${ }^{48}$

De todo lo anterior, puede concluirse que la justificación racional de un enunciado normativo - i.e. la mostración de su verdad- sólo puede lograrse a través de una argumentación que contenga, en alguno de sus pasos, al menos una proposición normativa. Y se trata de la mostración de su verdad toda vez que se parte de una concepción cognitivista de la ética y del derecho, entre muchas otras, por las varias razones expuestas por Cotta en su relevante trabajo citado más arriba, ${ }^{49}$ la principal de la cuales es que la adopción de una postura no-cognitivista en moral y en derecho significa, lisa y llanamente, una declaración de bancarrota de la razón ${ }^{50}$ en el campo de la praxis humana, declaración cuyas consecuencias inevitables no resultan aceptables, aun para los mismos defensores del no-cognitivismo. ${ }^{51}$

\section{DEBILIDADES DE LA JUSTIFICACIÓN ANALIZADA}

Luego de este excurso precisivo de las nociones centrales de la teoría del conocimiento práctico desde una perspectiva cognitivista, que es, por otra parte, la propuesta por el

47 Véase Blanché, R., Le raisonnement, París, PUF, 1973, p. 206.

48 Véase Gardies, J. L., Essai sur la logique des modalités, París, PUF, 1979, pp. 87 y ss.

49 Cotta, S., "Conoscenza e normativitá", cit., pp. 558 y ss.

50 La frase es de Larenz, K., Metodología de la ciencia del derecho, trad. de M. Rodríguez Molinero, Barcelona, Ariel, 1980 p. 233.

51 Véase Trigg, R., Morality Matters, Malden-Oxford-Carlton, Blackwell Publishing, 2005, pp. 1-10; asimismo: Graham, G., Eigth Theories of Ethics, Londres \& Nueva York, Routledge, 2004, pp. 1-16. 
mismo Cotta, corresponde desarrollar algunas observaciones al modelo de justificación racional de la normas propuesto por ese autor, observaciones que de ningún modo pueden restar mérito al enorme esfuerzo desarrollado por el profesor Cotta en su intento de proporcionar una fundamentación racional-cognitiva y veritativa de las normas éticas, en especial de las ético-jurídicas.

La primera de las observaciones que resulta conveniente efectuar al planteo que hemos estudiado, es la que corresponde, casualmente, al problema de la verdad en el cognitivismo ético. Cotta reconoce acertadamente que desde esa perspectiva es necesario hacerse cargo de la posibilidad de verdad -y de falsedad - en el conocimiento ético y rechaza, también acertadamente, ciertas concepciones limitadas del cognitivismo, en primer lugar la que reduce el cognitivismo al de los medios para lograr un fin ético. Cotta ejemplifica esta primera versión de cognitivismo limitado con las propuestas de G. H. von Wright (reglas praxeológicas) y A. Conte (reglas anancásticas). La segunda forma de cognitivismo limitado es la que establece una cierta relación entre el deber ser y el ser, pero en el plano de la experiencia empírica existencial, que remite a la constatación personal de las propias necesidades y preocupaciones materiales, psicológicas o espirituales, de las que se sigue por vía emotiva una valoración y la consiguiente consecuencia deóntica. Cotta cuestiona estas formas limitadas de cognitivismo por permanecer sólo en el interior del sujeto, con lo que, en definitiva, es la elección personal la que viene a determinar el contenido deóntico, a partir de una experiencia fenoménica y contingente. 52

Cotta propone en su reemplazo un cognitivismo, que a veces llama absoluto, de carácter noético-deóntico, basado en "un principio alético general de lo normativo", ${ }^{53}$ que parte de la existencia de la libertad como uno de los elementos esenciales que connotan la naturaleza humana y concluye

52 Cotta, S., "Conoscenza e normatività...", cit., pp. 560-562.

53 Ibidem, p. 564. 
con la afirmación de que la normatividad (...) es una necesidad del ser del hombre en cuanto es la garantía sine qua non de su continuidad en el curso de la existencia, en conformidad con el principium sese conservandi de todo ser. Tal necesidad es la causa ontológica de la normatividad (...). En consecuencia - continúa Cotta - la normatividad resulta connotada de una forma noético-deóntica: noética, puesto que el conocimiento del ser es indispensable, a menos de ignorar la propia causa; deóntica, puesto que responde a la necesidad de conservación del ser, con el "se debe" correspondiente. 54

$\mathrm{Y}$ concluye formulando un principio normativo fundamental y universal; "se debe (= todos deben) respetar al hombre en todo lo que él es ontológicamente". 55

Ahora bien, en primer lugar resulta claro, en estos y otros textos de Cotta, que cuando se refiere a la verdad y al carácter alético de la fundamentación, se está refiriendo exclusivamente a la verdad teórica y que en su sistemática no tiene lugar una noción —del tipo que sea- de verdad práctica. Esto queda demostrado con las referencias que Cotta hace a la necesidad de conservación de la coexistencia humana, o a la libertad como connotada por la naturaleza humana; en estos casos, así como en otros mencionados por este autor, se trata de afirmaciones de carácter puramente teórico o especulativo, donde las proposiciones veritativas: "la conservación de la coexistencia humana es necesaria" o "la naturaleza humana supone la libertad" describen un cierto estado de cosas humanas, sin referencias constitutivamente prácticas, en especial, práctico-normativas. Ahora bien, si no se considera la posibilidad de verdad en el caso de las proposiciones prácticas, no resulta posible construir un razonamiento argumentativo capaz de justificar proposiciones prácticas como las normas éticas o jurídicas, toda vez que, como se ha visto más arriba, sólo 
un razonamiento que incluya necesariamente proposiciones prácticas puede tener a una de ellas como conclusión.

El mismo Cotta niega la dimensión constitutivamente práctica de esos enunciados cuando escribe que "la coexistencia no es en sí misma, inmediatamente, un valor, pero llega a serlo cuando se lo asume, por la intencionalidad, como finalidad y criterio supremo de toda acción". ${ }^{56}$ Pero sucede que cuando algo no es práctico intrínsecamente, no puede llegar a serlo en virtud de un elemento extrínseco, como lo es la intención asumida por algún sujeto; en rigor, sólo el bien objetivo - bajo la formalidad de bien- puede ser objeto de la intención y fin de la praxis humana en cualquiera de sus dimensiones. Dicho en otras palabras, no se alcanza a ver cómo una realidad - la coexistencia- que no es en sí misma un valor, puede llegar a serlo por la sola mediación de un acto intencional de asunción, acto que, por definición, sólo puede serlo de la voluntad de un sujeto individual; si se está en presencia de una realidad en la línea del ser - y por lo tanto no de un valor- ¿cómo es posible que ella pase a la línea del valor sólo por un acto que le es extrinseco? 57

Todo esto, y varias otras aporias que se presentan en los textos analizados, es la consecuencia de la ausencia en el discurso del antiguo profesor de Roma de toda una dimensión del conocimiento, la del conocimiento práctico, que es la única capaz de proporcionar una justificación racional consistente a la dirección racional del obrar humano, en especial a la práctico —normativa-. Esto es así porque, tal como lo ha establecido la ciencia lógica, desde sus versiones más antiguas hasta las más contemporáneas, sólo con la mediación de premisas de carácter práctico es posible justificar racionalmente conclusiones de ese carácter, tal

$56 P J$, p. 18 (cursivas agregadas).

57 Véase Soaje Ramos, G., "Cotta, Sergio, Giustificazione e obbligatorietà delle norme” (reseña), Ethos, núm. 10-11, Buenos Aires, 1983, p. 388. 
como es el caso de las normativas. ${ }^{58}$ Es por eso que todos los intentos de justificar principios, normas o imperativos sin la mediación expresa de proposiciones prácticas, ${ }^{59}$ deben necesariamente incluir en la cadena argumentativa, aunque sea de modo implícito o supuesto, uno o más enunciados de ese carácter. De lo contrario, el intento de justificación resultará necesariamente fallido por ausencia del necesario vínculo ilativo -indispensable en todo proceso justificatorio- entre las premisas y la conclusión. 60

Y si se va a los ejemplos puestos por el mismo Cotta, es evidente que el razonamiento:

1) Puesto que el comportamiento C (v.gr. respetar la vida del inocente) es indispensable para la coexistencia,

2) Tú debes $C$ (v.gr. respetar la vida del inocente),

sólo tiene ilación - y puede integrar por lo tanto una justificación racional- si se está dando por supuesta la premisa deóntica (y por ende, práctica):

3) Todo lo que es indispensable para la coexistencia es debido.

Resulta también evidente, por otra parte, que en este razonamiento propuesto por Cotta, no puede tomarse la expresión es indispensable en el sentido de es necesario, ya que si algo es física o metafísicamente necesario no puede ser debido, ya que el deber supone la posibilidad de que las cosas no sean de ese modo. Pero si se toma es indispensable en el sentido de es deónticamente necesario, se estaría produciendo un sofisma de redundancia, afirmando que lo que es debido, es debido. Pero en cualquier caso, es indudable que sin una premisa que contenga un debe, no debe,

58 Se entiende aquí por "justificación racional" a "la indicación del motivo racional por el cual se admite una expresión en el seno de un conjunto dado de expresiones", Kalinowski, G., El problema de la verdad en la moral y en el derecho, cit., p. 132 n.

59 Véase, v.gr., Gardies, J-L., L'erreur de Hume, París, PUF, 1987, passim.

60 En este punto, véase Ziembinski, Z., Practical Logic, Dordrecht-Boston-Warsawa, D. Reidel Publishing Company-Polish Scientific Publishers, 1976, pp. 217 y ss. 
puede, etcétera, no será posible alcanzar la justificación racional de norma alguna.

En rigor, la debilidad del intento de justificación analizado radica en que se intenta justificar racionalmente las normas de modo veritativo, lo que es indudablemente correcto, ya que una justificación racional que culminara en una afirmación de la que no pudiera predicarse la verdad no justificaría nada, pero negando o dejando de lado la posibilidad de una verdad práctica, en especial de las proposiciones deóntico-normativas. ${ }^{61} \mathrm{Al}$ negar esta posibilidad se excluye del razonamiento justificatorio a las proposiciones deóntico-normativas - por considerarlas no susceptibles de verdad- que resultan indispensables para la conclusividad y la ilación del razonamiento. Por lo tanto, sin esta dimensión práctica del razonamiento no es posible justificar racionalmente normas, sean cuales sean las remisiones o referencias a la metafísica o la antropología.

Ahora bien, esta última afirmación hace necesaria una aclaración final, a los efectos de evitar algunas confusiones o malentendidos. Ella se refiere a que la necesidad de un elemento práctico en el razonamiento justificatorio de las normas, no implica la exclusión de toda remisión a tesis o enunciados propios de la metafísica o de la antropología filosófica. En efecto, si bien no es posible derivar lógicamente proposiciones normativas sólo de ese tipo de tesis o enunciados, resulta innegable que ciertas afirmaciones correspondientes a esos saberes resultan indispensables para cualquier razonamiento de la índole de los que estamos analizando. En este sentido, Soaje Ramos sostiene que resulta erróneo "conceptuar la ética filosófica como una suerte de corolario deductivo de la antropología filosófica, y a fortiori cuánto más equivocado es el presentarla como derivada deductivamente de la metafisica", para aclarar después que la ética filosófica "depende asimismo, aunque relativamente, de la antropología filosófica en la línea de la fundamenta-

61 Véase Kalinowski, G., La logique déductive, París, PUF, 1996, pp. 136. 
ción teórica de algunos de sus temas, incluso algunos entre los principales". 62

De este modo, es indudable que son necesarias ciertas afirmaciones de la antropología filosófica, v.gr. las correspondientes a la racionalidad y sociabilidad humanas, para la captación de ciertas tesis éticas referidas a los bienes humanos y las normas que les corresponden. ${ }^{63}$ Asimismo, algunas tesis metafísicas, ${ }^{64}$ v.gr. que el concepto trascendental de bien es coextensivo con el de ente, resultan indispensables para la estructura de los razonamientos que justifican normas. No se trata, por lo tanto, de excluir radicalmente las tesis metafísicas o antropológicas del discurso justificativo de las proposiciones normativas, sino sólo de no reducirse solamente a ellas, con exclusión de los principios propios de la ética filosófica.

\section{CONSIDERACIONES CONCLUSIVAS}

Luego de lo desarrollado hasta ahora, es posible arribar a las siguientes conclusiones principales:

a) Merece destacarse especialmente el ensayo, elaborado por Sergio Cotta en los trabajos aquí citados, destinado a encontrar y formular una justificación para las normas, concretamente para las normas juridicas, principalmente por su carácter racional y veritativo; en realidad, sólo es posible una justificación dotada de ambas cualidades, que resultan estrictamente indis-

62 Soaje Ramos. G., "Sobre antropología y ética filosófica. Sus relaciones epistémicas", Ethos, Buenos Aires, núm. 16-18, 1990, pp. 103 y 104. En otro párrafo, este autor escribe: "Esto no excluye que en la línea de fundamentación radical del saber ético, la metafísica en su ámbito propio ofrezca no sólo los principios ontológicos comunes a todos los otros saberes, sino también análisis y conclusiones que permiten fundar radicalmente tesis éticas"; p. 98.

63 Véase Gómez Lobo, A., Los bienes humanos. Ética de la ley natural, Santiago de Chile, Mediterráneo, 2006, pp. 86 y ss.

64 Véase, acerca de estas tesis, Kalinowski, G., L'impossible métaphysique, París, Beauchesne, 1981, pp. 143 y ss. 
pensables para la existencia misma de las realidades normativas.

b) Pero no obstante el valor de ese ensayo, la exclusión del concepto de verdad práctica lleva al autor a proponer una justificación integrada exclusivamente por proposiciones teóricas, antropológicas u ontológicas, lo que le impide una justificación adecuada de las proposiciones práctico-normativas, a raíz de la omisión de premisas que resultan indispensables para la ilatividad de los razonamientos.

c) Es probable que esta debilidad de la presentación del profesor Cotta se deba a la convicción de que la tesis de la imposibilidad de ilación lógica entre las proposiciones teóricas y las prácticas es tributaria exclusivamente de la filosofia de David Hume y de sus seguidores, los positivistas analiticos; en realidad, el error de Hume y sus seguidores fue el de reprochar a sus oponentes deducir normas sólo de proposiciones teóricas que constataban la existencia de Dios o describían la condición humana, excluyendo la posibilidad de la existencia -y la verdad- de proposiciones-principios prácticos autoevidentes que otorgan practicidad a todo el discurso y por lo tanto a sus conclusiones. 65

d) Otra explicación de esta ausencia en la sistemática del antiguo profesor de Roma de una filosofia práctica, en especial práctico-normativa, puede ser la que proviene de su adhesión - aunque con matices y correcciones- al lenguaje, la conceptualización y el approach propios de la fenomenologia existencial, que ha tenido siempre graves dificultades - cuando no insalvables - para la constitución de una filosofía de carácter constitutivamente práctico.

65 Véase Kalinowski, G., "Sur la distinction entre le descriptif et le normatif", Archives de Philosophie du Droit, París, núm. 33, 1988, p. 395. Véase, asimismo, Massini Correas, C. I., La falacia de la "falacia naturalista", Mendoza-Argentina, EDIUM, 1994, passim. 
e) Por supuesto que la insuficiencia que se ha apuntado no invalida el valor relevante de los desarrollos efectuados por el antiguo profesor de Roma, y en especial su defensa permanente del cognitivismo ético, de la racionalidad de las argumentaciones morales y jurídicas y de la necesidad de un justificación radical y decisiva de la normatividad ordenada al bien humano. 